\title{
Role model: Deborah Stalker
}

\section{The paediatrician talks to Helen Jones about working with vulnerable children through her roles in neonatal medicine and child protection}

\section{Helen Jones}

London, UK

"People think that paediatrics can be quite soft and fluffy, but it's hard work," says Deborah Stalker. "The intellectual challenge of diagnosing children who can't tell you what's wrong with them, or what their symptoms are, is really stimulating."

Until she retired in April, Stalker was a consultant paediatrician at Musgrove Park Hospital, Taunton, and the designated doctor for safeguarding children for Northern, Eastern, and Western Devon Clinical Commissioning Group. Having initially trained as a GP, she switched to neonatal medicine because she "enjoyed applying what was known around the science to each child."

"You can't do 'cookbook' medicine on babies because they are all so different," Stalker says. "What was really important was trying to achieve not just survival, but survival with the best possible outcome for babies who were often born in difficult circumstances.'

While working as departmental clinical lead, the role of named doctor for child protection became vacant. "No one else in the department wanted to do it, so essentially the buck stopped with me," she says. "It was something to get my teeth into. I really enjoyed working with other teams across the hospital and with the police and children's social care."

The combination of neonatal medicine and safeguarding is unusual, and most named doctors are community paediatricians. "The commonality is, I guess, dealing with extremely vulnerable patients and their families," Stalker says. "The satisfaction comes from improving the outcomes for these children-whether premature or abused, and often both-through close working with colleagues and other agencies."

Eventually Stalker gave up her neonatal practice, although still maintained some clinical practice in child protection, and took on the role of designated doctor for safeguarding children, supporting the local authority, police, local safeguarding boards, and named doctors. "Part of my role was chairing the serious case review subgroup in Devon, analysing what had gone wrong with a case, not to apportion blame, but to identify how we could do better next time and how to prevent it happening again," she says.
What she most enjoyed in that role was supporting the named doctors by providing advice on cases and helping with their training needs. "I think I have been described as being very supportive and giving advice where it's needed," she says. "Personally, I think I'm quite resilient and having done the named role I understand the challenges that they face. Having someone to support you and talk through a decision is crucial." She adds, "I pride myself on being as available as possible so that they can sleep at night. The role can be distressing and if you were working in isolation it would be a complete nightmare."

Stalker has now retired from her designated doctor role, but continues to do some work for the National Crime Agency as an expert witness in child protection and carrying out serious case reviews for local authorities on a consultancy basis. As she says, "You can't just suddenly stop when you have worked full on for 34 years."

\section{Nominated by Eleanor Thomas}

I first met Debbie when I was a senior house office in neonates in Bristol. She was one of the senior registrars and was a fantastic role model. Her calm, steady approach to all emergency situations made us feel supported and confident. Her dedication to paediatrics and her ability to combine work and family life have always been an inspiration to me.

Debbie was the designated doctor for safeguarding children in Devon and supported all of us who are working as named doctors in the area. Her knowledge of safeguarding is exemplary and we were lucky to be able to count on her for advice and guidance.

She was clearly dedicated to this role and was always able to help us think logically about difficult cases.

Eleanor Thomas is a consultant paediatrician and named doctor for safeguarding children at the Royal Devon and Exeter Hospital

To nominate someone who has been a role model during your medical career, send their name, job title, and the reason for your nomination to arimmer@bmj.com Published by the BMJ Publishing Group Limited. For permission to use (where not already granted under a licence) please go to http://group.bmj.com/group/rights-licensing/ permissions 